\title{
Gellan gum and polyvinylpyrrolidone (PVP) as binding agents in extrusion/spheronization pellet formulations
}

EDUARDO JOSÉ BARBOSA

HUMBERTO GOMES FERRAZ*

Department of Pharmacy

Faculty of Pharmaceutical Sciences

University of São Paulo

São Paulo Brazil
Accepted September 7, 2018

Published online October 4, 2018

\begin{abstract}
The aim of this work was to evaluate gellan gum as binder in pellet formulations, with theophylline as the model drug, in comparison with polyvinylpyrrolidone (PVP). A full $3^{2}$ factorial design was realized, with binder and diluent factors at three levels each. Pellets were produced by the extrusion/spheronization technique, and dried in a fluidized bed. Physical tests and dissolution tests were conducted. The results showed that the binder factor was not significant for pellet size and granulometry distribution. Rather, trends of a different response of gellan gum were identified, in comparison with PVP, in aspect ratio and dissolution tests: more round pellets were obtained in formulations with gellan gum, and more variable dissolution resulted when this polysaccharide was present. Therefore, if the usage of this compound in immediate release pellet formulations is verified, this justifies the interest in the development of sustained release systems using gellan gum.
\end{abstract}

Keywords: gellan gum, polyvinylpyrrolidone, pellets, extrusion, spheronization

In multiparticulate systems, drug dosage divided in subunits provides therapeutic advantages that include less variation in drug absorption and lower risk of gastrointestinal irritation compared to single unit dosage forms (1). In particular, pellets are a good choice for drug delivery because they offer interesting technological characteristics such as good flow properties and ease of coating application (1).

The most common way of producing pellets is extrusion/spheronization. In this technique, a powder blend is humidified to achieve adequate consistency for the extrusion step. During this operation, the material is compacted through a mesh for the production of cylindrical particles and is generally known as extrudate (2). Then, in the spheronization step, this material is submitted to frictional forces in a horizontal rotational disc. In this operation, spherical particles are formed and dried to obtain pellets (2).

To promote adhesion and cohesion between solid particles in humidification processes, some excipients are used to function as binders. A widely used compound for this purpose

*Correspondence; e-mail address: sferraz@usp.br 
E. J. Barbosa and H. G. Ferraz: Gellan gum and polyvinylpyrrolidone (PVP) as binding agents in extrusion/spheronization pellet formulations, Acta Pharm. 69 (2019) 99-109.

is polyvinylpyrrolidone (PVP), a synthetic polymer traditionally used by pharmaceutical companies in wet granulation processes (3).

Natural polymers can also perform this function. These materials traditionally arouse interest because of their versatility for application in pharmaceutical products, in addition to their tolerance by the organism (4). Among these compounds is gellan gum, a linear polysaccharide composed by the repetition of two glucose residues, glucuronic acid and rhamnose. Since its discovery, interesting properties have been identified, such as the ability to form viscous solutions and gels, as well as a three-dimensional crosslinked network in the presence of cations (5).

Native gellan gum has polymeric chains branched by the presence of acetate and glycerate groups, bonded to a glucose residue, denominated "high acyl", which can form deformable gels in solution. These groups can be removed by chemical treatment in alkaline medium, thereby originating the compound denominated "low acyl", which under adequate conditions forms a hard and brittle gel (5).

Several studies have evaluated the application of gellan gum in beads produced by ionotropic gelation or in tablet formulations (5). However, none of these works was aimed at evaluating its application in pellet formulations, although extrusion/spheronization is a widely used technique in the pharmaceutical industry (1).

Therefore, the aim of this work was to evaluate gellan gum as a binder in pellet formulations, with theophylline as the model drug, in comparison with PVP.

\section{EXPERIMENTAL}

\section{Materials}

Theophylline anhydrous was kindly provided by EMS S/A. Microcrystalline cellulose (MCC 101), Starch $1500^{\circledR}$ (Colorcon do Brasil Ltda), Maltodextrin (Valdequímica Produtos Químicos Ltda) and Mannitol (ISP do Brasil Ltda) were used as diluents. Low Acyl (LA;

Table I. Pellet formulations produced according to factorial design. Each composition comprises theophylline $30 \%$ and MCC $10160 \%$. Binder was added to the powder mixture from a solution prepared in advance

\begin{tabular}{ccc}
\hline Formulation & Binder & Diluent $(10 \%)$ \\
\hline 1 & LA & Starch $1500^{\circledR}$ \\
2 & LA & mannitol \\
3 & LA & maltodextrin \\
4 & PVP & Starch $1500^{\circledR}$ \\
5 & PVP & mannitol \\
6 & PVP & maltodextrin \\
7 & HA & Starch $1500^{\circledR}$ \\
8 & HA & mannitol \\
9 & HA & maltodextrin \\
\hline
\end{tabular}


E. J. Barbosa and H. G. Ferraz: Gellan gum and polyvinylpyrrolidone (PVP) as binding agents in extrusion/spheronization pellet formulations, Acta Pharm. 69 (2019) 99-109.

molecular weight range 2-3 $\left.\times 10^{5} \mathrm{Da}\right)$ and High Acyl gellan gum (HA; molecular weight range 1-2 × $\left.10^{6} \mathrm{Da}\right)(4)\left(\right.$ Kelcogel $^{\circledR}, \mathrm{CP}$ Kelco, Brasil), and Polyvinylpyrrolidone K30 (PVP) (BASF S/A) were used as binders.

\section{Design and preparation of formulations}

Base formulation is composed of theophylline $30 \%$, diluent $10 \%$, and MCC $10160 \%$, for batches of $80 \mathrm{~g}$. A full $3^{2}$ factorial design was elaborated with the aid of Statistica ${ }^{\circledR} 13$ (Dell Inc., USA) software, comprising two factors at three levels respectively: binder (LA gellan gum; PVP, HA gellan gum), and $10 \%$ diluent (Starch $1500^{\circledR}$, mannitol, maltodextrin), totalling 9 formulations, as shown in Table I.

For the application of binders, dispersions were prepared using purified water, with percentage of the compound in $\mathrm{m} / \mathrm{m}$ for a total of $100 \mathrm{~g}$ of dispersion. Concentration of PVP was $10 \%$, and that of LA and HA gellan gum was $0.5 \%$ and $0.05 \%$, respectively. Dispersions were subjected to heating under magnetic stirring, until temperature of $60{ }^{\circ} \mathrm{C}$ was reached. The system was then kept under stirring without heating for 1 hour.

A mixture of the powder and dispersion was prepared in a planetary domestic mixer in 5 minutes. In the end, moisture was determined twice with a Gehaka IV 2002 infrared balance (Gehaka, Brazil).

Extrusion was realized using a Caleva ${ }^{\circledR} 20$ extruder, set to $19 \mathrm{rpm}$, while spheronization was carried out with a Caleva ${ }^{\circledR} 250$ spheronizer, set to $700 \mathrm{rpm}$ for 3 minutes (Caleva Process Solutions, UK). Pellets were dried in a Hüttlin ${ }^{\circledR}$ Microlab fluidized bed (Hüttlin Instruments Company, Germany), with moisture determined twice with the Gehaka IV 2002 infrared balance (Gehaka, Brazil).

\section{Granulometry and friability}

Granulometric test was based on the study of Issa and collaborators (6), using sieves with meshes of 1.000, 0.900, 0.800, 0.710, 0.600, 0,500, 0.425, $0.300 \mathrm{~mm}$ and a collecting pan, in a Haver \& Boecker ${ }^{\circledR}$ EML Digital Plus (Germany) test sieve shaker.

To determine the dispersion of granulometric distribution, the accumulated fraction was first calculated from the lower to the highest sieve; then a squared model was obtained according to equation 1 , where $x$ is pellet size $(\mathrm{mm})$ and $y$ is the accumulated fraction (\%):

$$
y=a x^{2}+b x+c
$$

Span value was then calculated according to equation 2. $D_{90}, D_{50}$ and $D_{10}$ parameters were obtained from equation 1 . Thus, the closer to zero, the narrower was the granulometric distribution (7):

$$
\operatorname{Span}=\frac{D_{90}-D_{10}}{D_{50}}
$$

In the friability test, after granulometric separation, the sample was subjected to attrition with 200 spheres of glass in a Logan ${ }^{\circledR}$ FAB-2 friability tester (Somerset, USA), and then a new granulometric separation was performed under the same preconditions (6). Then, the fraction (\%) retained in each sieve was obtained, before and after attrition, and the difference modulus was calculated according to equation 3: 
E. J. Barbosa and H. G. Ferraz: Gellan gum and polyvinylpyrrolidone (PVP) as binding agents in extrusion/spheronization pellet formulations, Acta Pharm. 69 (2019) 99-109.

$$
\text { Difference modulus }=\sqrt{(\% \text { before attrition }-\% \text { after attrition })^{2}}
$$

Friability was considered the mean of the difference modulus, corresponding to the five largest fractions of granulometric distribution.

\section{Aspect ratio}

For this test, images were obtained using a Moticam $10^{\circledR}$ camera coupled to a Motic SMZ $168^{\circledR}$ optic microscope (Motic Incorporation Ltd) with a 10X/23 eyepiece. Measurements were performed with the aid of Motic Image Plus $2.0^{\circledR}$ software, using images of $0.75 \times$ magnification with pellets ranging from 0.800 to $0.710(\mathrm{~mm})$. Aspect ratio was calculated by dividing the value of the largest diameter of the pellet by the perpendicular diameter, which was repeated fifty times (50×) (8).

\section{Drug content and dissolution}

Theophylline content from the formulations was determined by UV spectrophotometry using a phosphate buffer solution of $\mathrm{pH} 7.5$ as medium. Absorbance values were obtained at the wavelength of maximum absorption at $271 \mathrm{~nm}$ using Cary 50 equipment (Varian Inc., USA).

Dissolution test was based on the method described in the United States Pharmacopoeia (9) for theophylline capsules. Pellets of 0.800 to $0.710 \mathrm{~mm}$ were put in size 0 hard gelatine capsules, containing the amount equivalent to $100 \mathrm{mg}$ of the drug. Tests were conducted in Logan ${ }^{\circledR}$ D-800 equipment (Logan, USA) using apparatus II, 50 rpm, with 900 $\mathrm{mL}$ of water at $37^{\circ} \mathrm{C}$ as dissolution medium. The drug was quantified by UV spectrometry at $268 \mathrm{~nm}$, using Cary 50 equipment (Varian Inc.).

Dissolution efficiency up to $1 \mathrm{~h}$ (DE $1 \mathrm{~h}$ ) was used as response, which was determined using the add-in program DDSolver, described in the work of Zhang et al. (10). In brief, for this parameter, the program calculates the area under the curve of the dissolution graph, based on the linear trapezoidal rule, considering the time from 0 to $t$, and the respective percentage of drug dissolved at time $t$. Thus, DE is determined as the ratio of this area to the area relative to the maximum percentage of drug dissolved over time, from 0 to $t$.

\section{Statistical analysis}

Factorial design was evaluated by Analysis of Variance (ANOVA) and by Multivariate Analysis (MA), using Statistica ${ }^{\circledR} 13$ (Dell Inc., USA) software.

In ANOVA, the responses were: the fraction of pellets (\%), referring to three granulometric ranges: $<0.71 \mathrm{~mm} ; 0.71-0.8 \mathrm{~mm}$; and $>0.8 \mathrm{~mm}$, friability, span, aspect ratio and DE $1 \mathrm{~h}$. The significance test was realized considering a confidence interval of $95 \%$.

MA was performed by Principal Components Analysis (PCA), using granulometric distribution of $<0.71 \mathrm{~mm}$ and $>0.8 \mathrm{~mm}$, aspect ratio, span and DE $1 \mathrm{~h}$ as entry variables. Two components, factors 1 and 2, selected according to Kaiser's criterion (11), were created for the construction of two-dimensional charts of formulations and variable projections. 
E. J. Barbosa and H. G. Ferraz: Gellan gum and polyvinylpyrrolidone (PVP) as binding agents in extrusion/spheronization pellet formulations, Acta Pharm. 69 (2019) 99-109.

\section{RESULTS AND DISCUSSION}

Characterization results are given in Table II. Values referring to span calculations are indicated in Table III. After drying, pellets had average final moisture of $5.86 \% \pm 0.81$.

Table II. Results of characterization tests of pellet formulations, used as responses to the statistical analysis

\begin{tabular}{ccccccc}
\hline \multirow{2}{*}{ Formulation } & \multicolumn{3}{c}{$\%$ retained in the range $(\mathrm{mm})$} & \multirow{2}{*}{$\begin{array}{c}\text { Friability } \\
(\%)\end{array}$} & $\begin{array}{c}\text { Aspect } \\
\text { ratio }\end{array}$ & $\begin{array}{c}\mathrm{DE} \\
1 \mathrm{~h}^{\mathrm{a}}\end{array}$ \\
\cline { 2 - 4 } & $>0.8$ & $0.8-0.71$ & $<0.71$ & & & \\
\hline 1 & 71.96 & 21.21 & 6.83 & $0.30 \pm 0.18$ & $1.19 \pm 0.13$ & 0.5923 \\
2 & 13.88 & 17.24 & 68.88 & $0.24 \pm 0.06$ & $1.30 \pm 0.22$ & 0.7743 \\
3 & 66.28 & 19.98 & 13.73 & $0.25 \pm 0.12$ & $1.18 \pm 0.11$ & 0.6418 \\
4 & 53.99 & 21.73 & 24.28 & $0.59 \pm 0.30$ & $1.44 \pm 0.31$ & 0.8367 \\
5 & 39.97 & 15.06 & 46.17 & $0.94 \pm 0.40$ & $1.34 \pm 0.22$ & 0.8302 \\
6 & 63.01 & 17.61 & 19.39 & $0.34 \pm 0.13$ & $1.29 \pm 0.20$ & 0.8237 \\
7 & 44.63 & 33.44 & 21.94 & $0.44 \pm 0.17$ & $1.27 \pm 0.21$ & 0.8275 \\
8 & 10.13 & 12.56 & 77.31 & $0.44 \pm 0.20$ & $1.25 \pm 0.18$ & 0.7557 \\
9 & 51.54 & 21.17 & 27.29 & $0.44 \pm 0.17$ & $1.26 \pm 0.15$ & 0.7052 \\
\hline
\end{tabular}

${ }^{\mathrm{a}} \mathrm{DE} 1 \mathrm{~h}$ - dissolution efficiency in 1 hour

Considering the binder factor, ANOVA did not reveal any significant difference between the results $(p>0.05)$. However, in the sphericity and dissolution tests, it was noted that the trend of gellan gum produced a different response when compared to PVP. Therefore, this factor did not influence the particle size and friability. Major differences are related to the pellet form and drug release. Regarding the diluent factor, different results related to pellet size and granulometric distribution were obtained $(p<0.05)$.

Table III. Squared models and the corresponding span value, used for the characterization of granulometric dispersion

\begin{tabular}{cccc}
\hline Formulation & Model & $R^{2}$ & span \\
\hline 1 & $y=266.63 x^{2}-192.66 x+32.319$ & 0.9851 & 0.48 \\
2 & $y=-65.749 x^{2}+186.55 x-16.09$ & 0.9569 & 1.54 \\
3 & $y=220.39 x^{2}-130.24 x+16.523$ & 0.9856 & 0.53 \\
4 & $y=97.72 x^{2}+41.319 x-24.947$ & 0.9070 & 0.69 \\
5 & $y=49.318 x^{2}+69.556 x-10.38$ & 0.9719 & 1.05 \\
6 & $y=185.83 x^{2}-83.68 x+6.4096$ & 0.9764 & 0.60 \\
7 & $y=72.998 x^{2}+82.153 x-40.555$ & 0.9119 & 0.65 \\
8 & $y=-102.81 x^{2}+225.96 x-20.514$ & 0.9695 & 1.59 \\
9 & $y=112.59 x^{2}+12.758 x-19.164$ & 0.9835 & 0.64 \\
\hline
\end{tabular}


a)

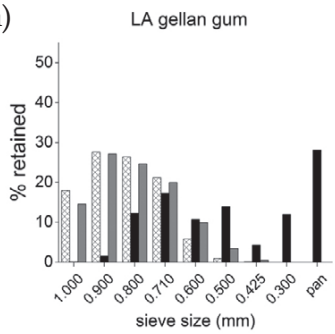

b)

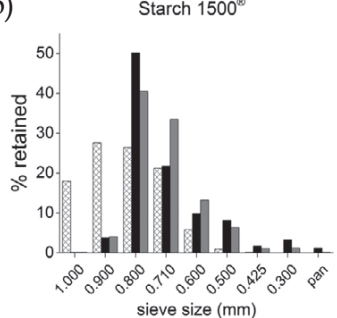

PVP

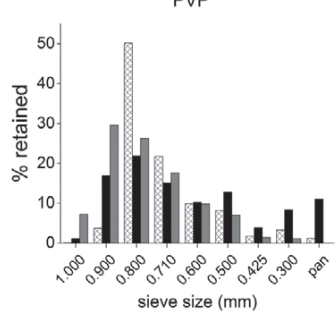

Mannitol

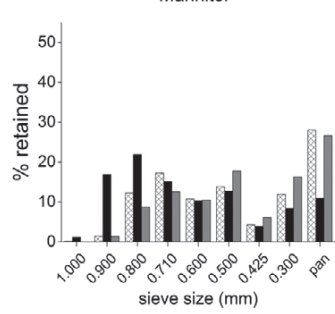

HA gellan gum

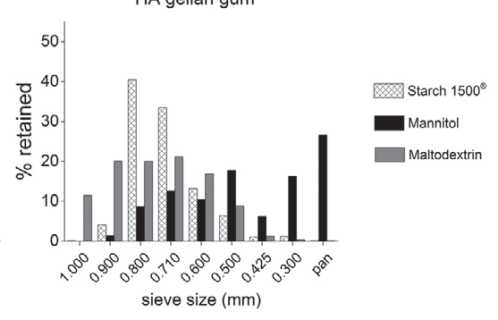

Maltodextrin

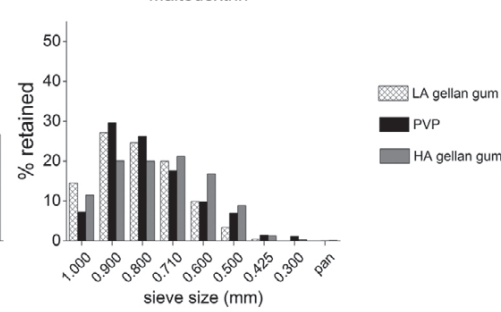

Fig. 1. Granulometric distribution of pellet formulations, as \% retained in the function of sieve size, according to factorial design factors: a) binder, b) diluent.

In MA, joint assessment of the influence of factors on the responses permitted separation of formulations into similar groups. Thus, this approach enabled a systematic identification of trends of gellan gum responses compared to PVP, in addition to complementing separate evaluation of the factors performed by ANOVA.

\section{Granulometry and friability}

Pellets were mostly retained in sieves larger than $0.71 \mathrm{~mm}$, with little powder present at the bottom (Fig. 1). According to ANOVA, the binder factor had no significant influence on the response. Although much smaller quantities of gellan gum were present in the formulations compared to PVP, the presence of binders did not contribute to obtaining small pellets.

In Fig. 1, the results relating to the diluent factor $(b)$ indicate that the presence of mannitol was related to a different response when compared to Starch $1500^{\circledR}$ and maltodextrin $(p<0.05)$. For these formulations, larger quantities of powder were obtained after the drying of pellets; in addition, larger pellets were not obtained when gellan gum was used, compared to formulation 5 when PVP was present.

In Table III, square models describe the accumulated fraction of pellets from the smallest to largest sieves of each formulation, and the corresponding span value. A positive or negative value of "a" in equation 1 indicates the tendency of the granulometric distribution to be located in larger or smaller sieves, respectively. Thus, according to the results, mannitol formulations 2 and 8 had the highest proportion of pellets retained in smaller sieves, showing extensive distribution, since the larger the value of the span, the more dispersible was the granulometric distribution. 
E. J. Barbosa and H. G. Ferraz: Gellan gum and polyvinylpyrrolidone (PVP) as binding agents in extrusion/spheronization pellet formulations, Acta Pharm. 69 (2019) 99-109.

Therefore, though there was $10 \%$ diluent in the formulations, the presence of mannitol contributed to the formation of small pellets and powder after drying.

Regarding friability, there was no considerable wear of the pellets after attrition, since all the formulations had, on average, values less than $1 \%$. In addition, ANOVA did not indicate any significant difference between the results, for either the binder or diluent factors. Thus, like in granulometry, gellan gum had an advantage compared to PVP, since it was possible to obtain equivalent pellets with gellan in a much lower proportion in the formulations.

a)

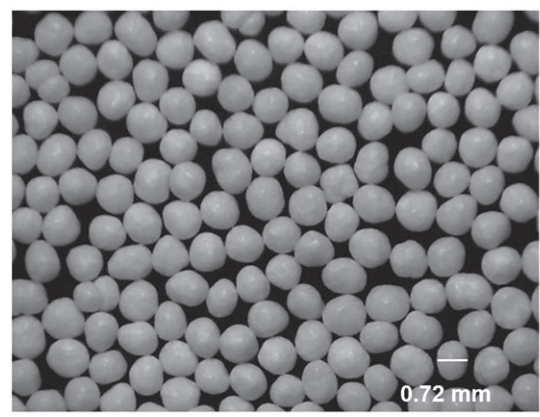

b)

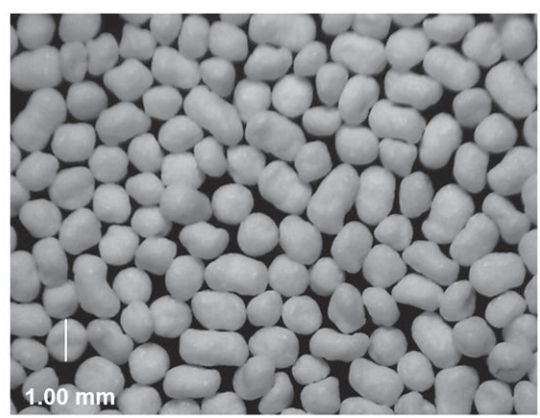

Fig. 2. a) Pellet images of formulation 3 (low acyl gellan gum, maltodextrin) and b) formulation 4 (PVP, Starch $1500^{\circledR}$ ), with 1.18 and 1.44 aspect ratio values, respectively.

\section{Aspect ratio}

According to the results, pellets in the 0.8 to $0.71 \mathrm{~mm}$ range showed an average aspect ratio of $1.28 \pm 0.08$. As stated by Podczeck and coworkers (8), a value of 1.02 , obtained from two-dimensional images, would correspond to a practically spherical particle; as this result is rarely achieved in practice, deviations have to be considered. Thus, according to the authors, a value between 1.1 and 1.2 can be considered to be sufficiently rounded.

As indicated by the results in Table II, only formulations 1 and 3 gave results within this range, indicating that the majority of pellets showed varied forms that differed from the round shape. This can be exemplified by the images in Fig. 2, where more spherical pellets can be observed (a), but also pellets with elongated or curved shapes (b).

In the statistical evaluation, ANOVA indicated that only the binder factor was significant for the aspect ratio $(p<0.05)$, although the result is very close to the critical value. Thus, under the conditions employed, gellan gum showed a tendency to produce more spherical pellets.

\section{Dissolution}

Dissolution profiles displayed in Fig. 3 show that $80 \%$ of drug release was reached in 1 hour for most of the formulations. Exceptions are the results relating to 1 (LA gellan, Starch $1500^{\circledR}$ ) and 3 (LA gellan, maltodextrin), which presented the lowest values among all the formulations. 
E. J. Barbosa and H. G. Ferraz: Gellan gum and polyvinylpyrrolidone (PVP) as binding agents in extrusion/spheronization pellet formulations, Acta Pharm. 69 (2019) 99-109.

a)

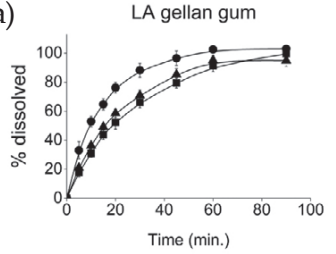

b)

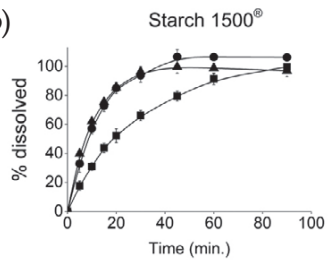

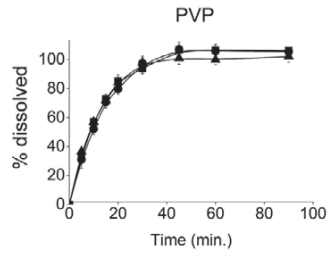
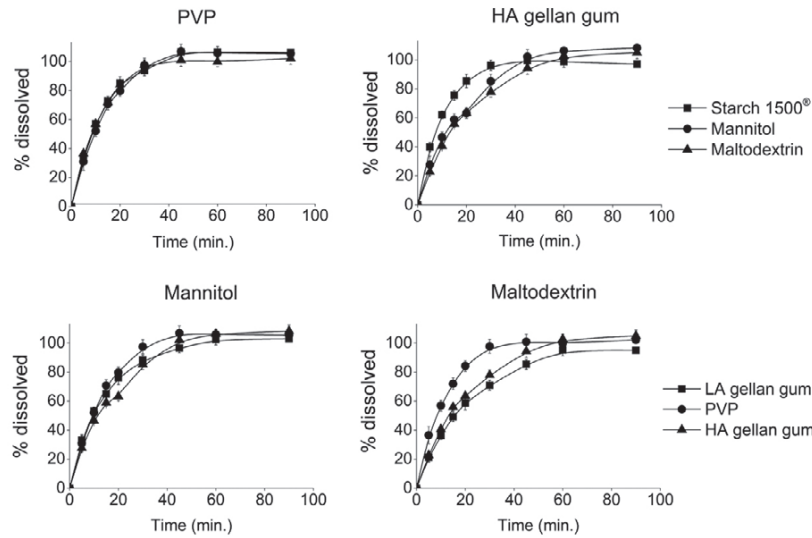

Fig. 3. Dissolution profiles of pellet formulations according to factorial design factors: a) binder, b) diluents.

According to the results given in Table II, it can be seen that formulations with PVP $(4,5$ and 6) had averagely higher DE than those with gellan gum, indicating a trend of faster drug release when PVP was present.

In the response surface chart (Fig. 4a), the effect attributed to the binder in dissolution may also be noticed, indicating the major effect of gellan gum in drug release compared to PVP. This can be also seen in the marginal means chart (IC $95 \%$ ) (Fig. 4b), which shows a small difference between the results of LA and HA gellan gum.

According to the literature, gellan gum molecules, when in solution, form double helix chains after heating and cooling, being stabilized by the presence of mono or divalent cations, thus forming aggregates that compose a three-dimensional network of crosslinked gel (12). According to Silva and coworkers (13), as HA gellan gum has a more branched chain, the steric hindrance of bulky groups within the double-helix implies a smaller proportion of molecules associated with this structure, compared to LA gellan

a) Fitted Surface; Variable: DE $1 \mathrm{~h}$ MS Residual=,0048365

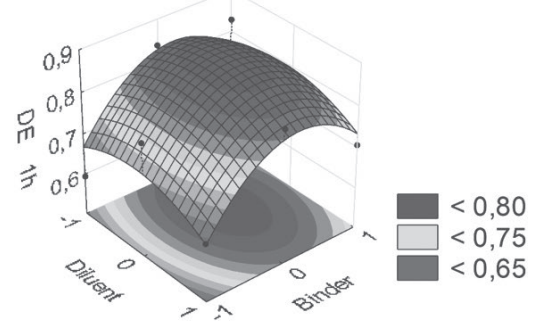

b) Marginal Means and Conf. Limits (95\%); DV: DE $1 \mathrm{~h}$ MS Error $=, 0048365$

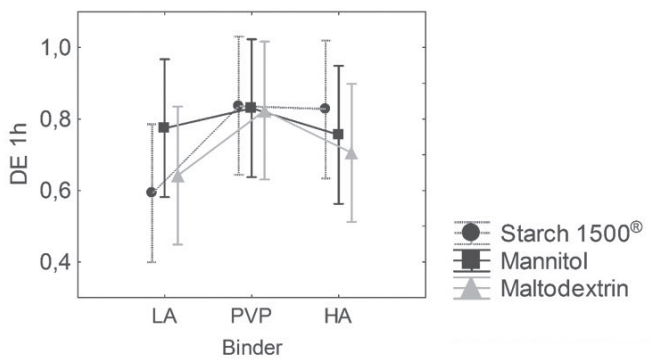

Fig. 4. a) Response surface chart and b) marginal means (IC $95 \%$ ) for dissolution efficiency up to $1 \mathrm{~h}$. 
gum. As drug release modulation by this polymer is related to the formation of these aggregates (14), the degree of interaction between the chains may have influenced drug release, which was reflected in the difference between polysaccharide formulation results. Thus, the greater molecule pairing with LA gellan could favour the tendency of retarding theophylline release, compared to HA gellan.

Another factor that may be related to the results is the swelling capacity of these compounds. As stated in the work of Maderuelo and coworkers (15), one possible factor that may control drug release from a hydrophilic matrix is the swelling of the polymer. In this case, according to the authors, the side chains of the molecule are very important to the hydration rate and swelling of the compound. Hence, as reported in the work of Silva and coworkers (13), HA gellan has a greater capacity of swelling than LA. Thus, the branched chain present in HA gellan gum may have favoured its hydration and swelling, which could be also associated with the tendency of faster drug release, compared to LA gellan.

\section{Multivariate analysis}

Conforming to the results provided in Table IV, component 1 is related to granulometry and span, while component 2 is related to the aspect ratio and DE. These two variables can explain $95 \%$ of the results according to the two-dimensional charts of the formulations and of the variables (Fig. 5).

Still, in Fig. 5a, two principal groups can be seen opposite to each one on the horizontal axis of component 1: formulations 1 and 3, which represent a larger fraction of pellets in the range $>0.8 \mathrm{~mm}$ and a lower span value, and the group composed of 2 and 8 , which represent a larger fraction in the $<0.71 \mathrm{~mm}$ range, and a higher span value. A third intermediate group composed of the remaining pellets can be also seen.

In addition, formulations with mannitol $(2,5$ and 8$)$ are those located nearest to the left side of the axis, indicating a more extensive distribution of the granulometry and a larger proportion of pellets retained in smaller sieves than the remaining ones.

Regarding the principal component 2 , it can be noticed that, with the exception of formulation 7 , all the others with gellan gum $(1,2,3,8$ and 9) are located above the plane that divides the vertical axis, while those with PVP are under the same plane. Thus, although ANOVA did not indicate any significant difference between the results, it can be

Table IV. Variable contributions to the estimation of principal components 1 and 2

\begin{tabular}{ccc}
\hline \multirow{2}{*}{ Variable } & \multicolumn{2}{c}{ Component (Eigen-value) } \\
\cline { 2 - 3 } & \multicolumn{1}{c}{1} & 2 \\
\cline { 2 - 3 }$>0.8 \mathrm{~mm}$ & 0.279354 & $(1.513915)$ \\
\hline$<0.71 \mathrm{~mm}$ & 0.276946 & 0.042851 \\
Aspect ratio & 0.065785 & 0.463100 \\
Span & 0.269004 & 0.071365 \\
DE 1 h & 0.108910 & 0.365319 \\
\hline
\end{tabular}


E. J. Barbosa and H. G. Ferraz: Gellan gum and polyvinylpyrrolidone (PVP) as binding agents in extrusion/spheronization pellet formulations, Acta Pharm. 69 (2019) 99-109.

a)

Projection of the cases on the factor-plane $(1 \times 2)$ Cases with sum of cosine square $>=0,00$

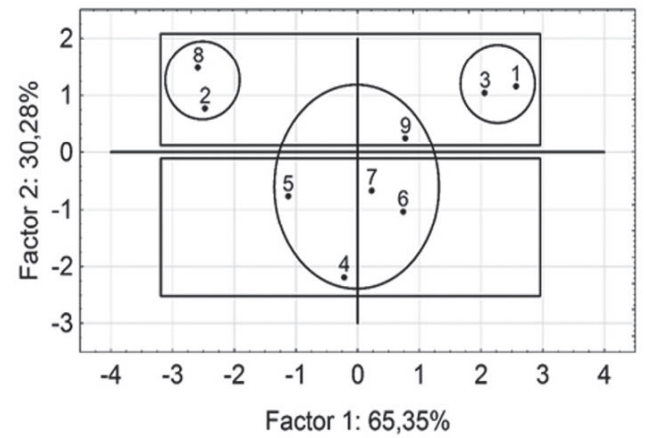

b)

Projection of the variables on the factor-plane $(1 \times 2)$

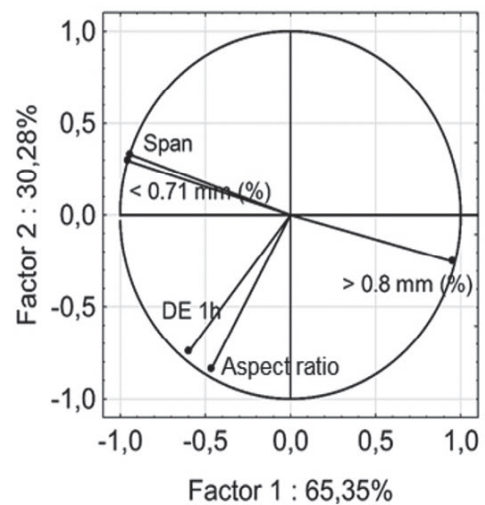

Fig. 5. a) Projections of formulations and b) variable effect on the two-dimensional plane of the principal components.

observed that gellan had a tendency of influencing the aspect ratio (making more round pellets) and dissolution (retarding drug release), compared to PVP.

Thus, although gellan gum application may have advantages for characteristics such as granulometry, friability, and aspect ratio, the usage of this polymer for dissolution might become more critical, since even in a much lower proportion in the formulations, the amount applied was sufficient to cause a greater variation in dissolution results. This could have a stronger impact in the case of a low solubility drug, which, on the other hand, justifies the interest in the potential of this compound for the development of sustained release systems.

\section{CONCLUSIONS}

According to the results of this study, it was verified that gellan gum may have advantages for physical characteristics of the pellets when it is applied as a binder compared to PVP. However, in the dissolution test, a stronger trend was noticed of this polysaccharide of influencing drug release compared to the results for formulations with PVP, which justifies the interest in this compound for the development of sustained release products.

Acknowledgements. - The Authors acknowledge Capes and Fipfarma for financial support.

\section{REFERENCES}

1. S. Muley, T. Nandgude and S. Poddar, Extrusion-spheronization a promising pelletization technique: In-depth review, Asian. J. Pharm. Sci. 11 (2016) 684-699; https://doi.org/10.1016/j.ajps.2016.08.001

2. V. R. Sinha, M. K. Agrawal, A. Agarwal, G. Singh and D. Ghai, Extrusion-Spheronization: Process Variables and Characterization, Crit. Rev. Ther. Drug Carrier Syst. 26 (2009) 275-331; https://doi. org/10.1615/CritRevTherDrugCarrierSyst.v26.i3.20

3. A. H. Kibbe, Povidone, in Handbook of Pharmaceutical Excipients (Eds. R. C. Rowe, P. J. Sheskey, M. E. Quinn), 6th ed., Pharmaceutical Press, London 2009, pp. 581-585. 
E. J. Barbosa and H. G. Ferraz: Gellan gum and polyvinylpyrrolidone (PVP) as binding agents in extrusion/spheronization pellet formulations, Acta Pharm. 69 (2019) 99-109.

4. V. D. Prajapati, G. K. Jani, B. S. Zala and T. A. Khutliwala, An insight into the emerging exopolysaccharide gellan gum as a novel polymer, Carbohydr. Polym. 93 (2013) 670-678; https://doi. org/10.1016/j.carbpol.2013.01.030

5. T. Osmałek, A. Froelich and S. Tasarek, Application of gellan gum in pharmacy and medicine, Int. J. Pharm. 466 (2014) 328-340; https://doi.org/10.1016/j.ijpharm.2014.03.038

6. M. G. Issa, L. Pessole, A. I. Takahashi, N. A. Filho and H. G. Ferraz, Physicochemical and dissolution profile characterization of pellets containing different binders obtained by the extrusion-spheronization process, Braz. J. Pharm. Sci. 48 (2012) 379-388; https://doi.org/10.1590/S1984-82502012000300004

7. S. Bialleck and H. Rein, Preparation of starch-based pellets by hot-melt extrusion, Eur. J. Pharm. Biopharm. 79 (2011) 440-448; https://doi.org/10.1016/j.ejpb.2011.04.00.

8. F. Podczeck, S. R. Rahman and J. M. Newton, Evaluation of a standardised procedure to assess the shape of pellets using image analysis, Int. J. Pharm. 192 (1999) 123-138; https://doi.org/10.1016/ S0378-5173(99)00302-6

9. United States Pharmacopoeia 37, NF 32, 37th ed, The United States Pharmacopeial Convention, Inc., Rockville 2013, p. 4911.

10. Y. Zhang, M. Huo, J. Zhou, A. Zou, W. Li, C. Yao and S. Xie, DDSolver: An Add-In Program for Modeling and Comparison of Drug Dissolution Profiles, AAPS J. 12 (2010) 263-271; https://doi. org/10.1208/s12248-010-9185-1

11. I. T. Jolliffe, Principal Component Analysis, 2nd ed., Springer, New York 2002, pp. 111-115.

12. E. R. Morris, K. Nishinari and M. Rinaudo, Gelation of gellan - A review, Food Hydrocoll. 28 (2012) 373-411; https://doi.org/10.1016/j.foodhyd.2012.01.004

13. D. Awanthi De Silva, L. A. Poole-Warren, P. J. Martens and M. in het Panhuis, Mechanical characteristics of swollen gellan gum hydrogels, J. Appl. Polym. Sci. 130 (2013) 3374-3383; https://doi. org/10.1002/app.39583

14. V. M. O. Cardoso, B. S. F. Cury, R. C. Evangelista and M. P. D. Gremião, Development and characterization of cross-linked gellan gum and retrograded starch blend hydrogels for drug delivery applications, J. Mech. Behav. Biomed. Mater. 65 (2017) 317-333; https://doi.org/10.1016/j.jmbbm.2016.08.005

15. C. Maderuelo, A. Zarzuelo and J. M. Lanao, Critical factors in the release of drugs from sustained release hydrophilic matrices, J. Control. Release 154 (2011) 2-19; https://doi.org/10.1016/j.jconrel.2011.04.002 